\title{
A Follow-up Study on the Performance, Outcome and present status of patients treated Under 'RNTCP' in a slum area of Kolkata
}

\author{
Tushar Kanti Saha ${ }^{1}$, Amitabha Chattopadhyay ${ }^{2}$, Sonali Sain ${ }^{3}$,Kakoli Boral ${ }^{4}$, \\ Shamima Yasmin ${ }^{5}$, Rivu Basu ${ }^{6}$ \\ 1(Assistant Professor, Department of Community Medicine, NRS Medical College ,West Bengal, India) \\ 2(Assistant Professor, Department of Community Medicine, R.G. Kar Medical College ,West Bengal, India) \\ 3,4(Assistant Professor, Department of Community Medicine, NRS Medical College, West Bengal, India) \\ 5,6(Demonstrator, Department of Community Medicine, NRS Medical College ,West Bengal, India)
}

\begin{abstract}
Background: Revised National Tuberculosis Control Programme (RNTCP) was introduced in India in 1993, as a pilot project but the full-fledged programme was started in 1997. Very few long-term follow-up studies of patients at one year after completing treatment under DOTS are available. Methodology: A cross sectional observational study was done to assess the performance and treatment outcome of patients under RNTCP and to determine the status of the tuberculosis (TB) patients after one year of completion of treatment under RNTCP. Data were collected by review of records from TB patients registered at the DOTS centre of TB Unit, Urban Health Centre, Chetla, Kolkata and subsequently followed up at their home. Statistical Analysis was done by proportions and Chi-square test. Results: Outcome of 82 registered patients during the study period at the end of completion of their treatment was: treatment success (cured plus treatment completed)$90.2 \%$, default- $6.1 \%$, death- $2.4 \%$ and treatment failture-1.2\%. On follow-up at one year, only 60 (73.2\%) patients were traced. The follow-up status of 60 patients revealed that all patients were asymptomatic and had no history of relapsed/death. Conclusion: Treatment under RNTCP was effective as revealed by the results at one year follow-up.
\end{abstract}

Key Words: Assessment of performance, DOTS, RNTCP, relapse, treatment outcome.

\section{Introduction:}

Though the National Tuberculosis Control Program (NTCP) was in existence since 1962, tuberculosis remained the leading infectious cause of death in India. Around 2.2 million people were detected to have tuberculosis every year (25\% of the global cases) and over 0.5 million died of this disease every year (17\% of global TB deaths). ${ }^{1}$ Total population suffering from active disease in India was 14 million of which 3 to 3.5 million were positive for sputum ( $20 \%$ to $25 \%$ of total). About one million sputum-positive cases were added every year. ${ }^{2}$

With this background, in 1992 the Government of India together with WHO and SIDA reviewed the National Program and launched its revised strategy, i.e., Revised National Tuberculosis Control Program (RNTCP). The RNTCP came into existence by formulating and adopting the internationally recommended DOTS strategy as a most systemic and cost-effective approach to revitalise the TB control program in India. To achieve the goal, first objective was to achieve and maintain a cure rate of at least $85 \%$ among newly detected infectious (new sputum smear-positive) cases and to achieve and maintain detection of at least $70 \%$ of such cases in the population. Treatment success rate had been increased from $25 \%$ to $86 \%$, death rate had been brought down seven-fold, from 29 percent to 4 percent. ${ }^{\mathbf{3}, 4}$

Despite high cure rates, several queries and doubts had been raised about the effectiveness of RNTCP regimens, including inadequate diagnosis, method of administration, wrong categorisation and possibility of increased rate of multidrug-resistant tuberculosis (MDR -TB). With this background, and fortified by the fact that few study had been carried out specially in this part of the country, this cross-sectional study was conducted among the patients who were treated in TB Unit of Urban Health Centre (UHC), Chetla with the following objectives: 1) To assess the performance and treatment outcome of patients under RNTCP, 2) To determine the status of the tuberculosis (TB) patients after one year of completion of treatment under RNTCP.

\section{Materials And Methods:}

It was a cross-sectional study carried out in a slum area of Kolkata inhabited by people of poor socioeconomic status. Study was conducted in January - February 2009. A total of 82 patients, who had been registered over a period of one year from January - December 2007 at the DOTS centre, in UHC, Chetla, Kolkata were studied. Information about their name, age, sex, address, initial sputum smear result, treatment 
category, date of start of treatment, sputum smear result during and at the end of their treatment and outcome was collected from the Tuberculosis Register (TB Register) maintained at the DOTS centre. All the patients along with their addresses were approached, door-to-door, in their homes with the help of a Health Worker. Consent was taken from the patients who were traced after one year of treatment to participate in the study. Information on patient's socio-demographic and other variables (e.g. literacy, occupation, per capita monthly income, personal habits like smoking/drinking/sexual promiscuity, perception of the efficacy of DOTS regimen and reasons for default) were collected by interviewing patients or their close contacts at the patient's residence in a relaxed and conducive atmosphere by using a pre-designed, semi-structured interview schedule. The modified Prasad classification was used for socio-economic class of patients. Patients were evaluated clinically with the help of a pre-designed proforma. Data were scrutinized for completeness and consistency. Collected data were then analyzed and statistical tests were done with the help of Microsoft Excel \& Epi-info (3.5.1) software. Test for the statistical significance was applied by using $\mathrm{x}^{2}$ test for analyzing the difference between the two proportions $(P<0.05$ was considered significant).

\section{1)From records analysis}

\section{Results:}

It was found that of the total of 82 patients who were registered in the year 2007, most of the patients (64.6\%) were male and $48.8 \%$ were under 30 years of age (Fig 1).

Among 82 patients, total new cases were $63(76.8 \%)$ and $47(57.3 \%)$ were new pulmonary cases. Overall $9.8 \%$ were relapse, $2.4 \%$ failure, $2.4 \%$ treatment after default and $8.5 \%$ were other category. Out of the total 82 cases, pulmonary cases were $63(76.8 \%$ ) and extra pulmonary cases were $19(23.2 \%)$ (Fig 2).

Among the 49 Pre-treatment sputum positive cases, $37(73.0 \%)$ were new sputum smear-positive. It was observed that sputum conversion rate for new sputum-positive TB cases at 2 or 3 months was $73.0 \%$, and among all 49 sputum smear-positive cases it was $73.5 \%$ (Table 1).

All the 82 patients put on DOTS were analyzed for treatment outcome. Out of total 82 patients, 51(62.2\%) were given Category I regimen, 18 (22.0\%) Category II regimen and 13 (15.9\%) Category III regimen. Treatment success rate was highest for new (category I) sputum positive PTB patients, $97.3 \%$ (36 of 37). Treatment completion was achieved in $84.2 \%$ (16 of 19) of EPTB patients and 93.8\% (45 of 48) of all sputum positive PTB patients. Overall treatment success was noted in $90.2 \%$ (74 of 82) of patients. Altogether $6.1 \%$ patients defaulted from treatment. Treatment failure and deaths were reported in $1.2 \%$ and $2.4 \%$ patients, respectively (Table 2).

\section{2) Follow-up of Study Group}

Out of 82 patients, only 60 (73.2\%) patients could be traced. Category wise break-down of 60 patients was: Category I: 35, Category II: 14 and Category III: 11. Out of a total of 82 patients, 16 (19.5\%) could not be traced because of migration, while $6(7.3 \%)$ could not be traced out due to improper address. Analysis of these 60 patients revealed that all the patients were asymptomatic/ no history of relapse/death. Socio-demographic information of study population revealed almost $43.3 \%$ were educated up to primary and $28.3 \%$ were illiterate and near about $70.0 \%$ belong to nuclear family. Occupation distribution showed that nearly $50.0 \%$ of patients were labourers, few from either business or Government sector. More than half of the patient were from very poor socio-economic family and per capita monthly income rupees less than 500 (56.67\%) (Table 3).

The present study showed that $94.0 \%$ of study population that was followed up was compliant to DOTS. On asking the reasons for not taking treatment among the non compliance, it was observed that majority of patients on DOTS stopped treatment because of side effects of drugs. The other reasons were Workrelated/Alcohol/Domestic Problems/Stigma related and lack of knowledge about various aspects of TB and its treatment. The three aspects of health education asked to all tuberculosis patients were about effectiveness of DOTS, knowledge about toxicity of drugs and importance of completion of therapy. These and also the compliance of DOTS were high among those who were literate and have good knowledge about various aspects of the disease.

\section{Discussion:}

The present study was carried out to determine the status of tuberculosis patients treated under RNTCP, after one year of completion of treatment. The study revealed a treatment success (cured plus treatment completed) in Category I, Category II, Category III patients of $94.1 \%, 83.3 \%$, and $84.6 \%$, respectively. The overall treatment success was $90.2 \%$. A study from Delhi reported treatment success rate in Category I and Category II patients were $91.0 \%$ and $73.0 \%$, respectively. ${ }^{3}$ Similar treatment success was also reported in other studies from Mumbai ${ }^{4}$, Lucknow ${ }^{5}$, Bangladesh ${ }^{6}$, Delhi ${ }^{7}$ and Karnataka. ${ }^{8}$ However, a study from Bangalore ${ }^{9}$ reported a low treatment success of $67.9 \%$ in Category I patients, which was likely due to high default rate. 
Default rate in the present study was 5.9\%, 5.6\% and 7.7\% in Category I, Category II and Category III patients, respectively with an overall default rate of $6.1 \%$. A study from Delhi reported a treatment default rate of $8.5 \%$ in both Category I and Category II with an overall treatment default rate of $7.7 \% .^{3}$ In Mumbai treatment default rate was reported in $7.1 \%$ and $8.9 \%$ in Category I and Category II patients, respectively. ${ }^{4}$ Another study from Lucknow reported treatment default rate of 3.0\% and 9.3\% in Category I and Category II patients, respectively. ${ }^{5}$ A study from Bangladesh ${ }^{6}$ reported a treatment default rate of $10.0 \%$ in new smear positive cases while it was reported as $6.6 \%$ in a study from China. ${ }^{10} \mathrm{~A}$ subsequent study from Delhi reported a treatment default rate in all the categories of patients ranging from $6.7 \%$ to $9.3 \% .^{7}$

The present study revealed treatment failure in $1.2 \%$ patients only, while a study from Delhi reported an overall treatment failure in $1.6 \%$. Another study from Bangalore reported treatment failure in $5.2 \%$ in Category I. ${ }^{9}$ Treatment failure was reported as $1.0 \%$ and $4.2 \%$ in new smear positive and retreatment cases from Mumbai ${ }^{4}$ respectively; while it was $0.6 \%$ and $2.6 \%$ from Lucknow. ${ }^{5}$ Another study from Bangladesh ${ }^{6}$ reported treatment failure in new smear positive as $2 \%$. A subsequent study from Delhi reported treatment failure in $4.6 \%$ in all the categories. ${ }^{7}$ In the present study, overall death rate was found to be $2.44 \%$. In other studies, death rate was reported ranging from $1.7 \%$ to $6.5 \%$ patients. ${ }^{3-6,8,9}$

The percentage of asymptomatic patients in this study after one year was $100 \%$. A follow-up study at 18 months from Delhi RNTCP at Lucknow by S.K. Verma et al reported that $97.2 \%$ of patients were asymptomatic, ${ }^{12}$ which was similar to the present study. In another 18 months follow-up study from South Africa, ${ }^{11}$ only $62 \%$ of new sputum smear positive patients were asymptomatic. This could be explained as $53 \%$ of patients in that study were HIV sero-positive. A two years follow-up study from Karnataka reported that $79.6 \%$ of new sputum smear positive patients were asymptomatic. ${ }^{8}$

Another two year follow-up study from Mumbai ${ }^{4}$ that included both new sputum smear positive as well as retreatment cases, reported that $83 \%$. of patients were asymptomatic. The two and- a-half year follow-up study from Bangalore 9 found that asymptomatic patients was $84.5 \%$.

In present follow-up study, $19.5 \%$ patients could not be traced due to migration. An one-and-a-half year follow-up study from Delhi reported that, $25.8 \%$ patients could not be traced due to migration. ${ }^{12}$ Another 18 months follow-up study from South Africa reported that $19 \%$ patients had migrated but the reasons for migration were not specified. ${ }^{11}$ A two years follow-up study from Mumbai reported that $10.7 \%$ patients could not be traced without specifying any reasons ${ }^{4}$.

Another two-and-half years follow-up study from Bangalore ${ }^{9}$ reported that about $24.2 \%$ patients could not be traced. This was due to temporary or permanent migration of patients to their native villages. In the present study, $7.3 \%$ patients could not be traced due to improper addresses, maintained in the TB register. None of the above follow-up studies mentioned the relevance of improper addresses. Improper address may be due to low socio-economic status of our patients who live in temporary shelters or in slum areas and lack of appropriate permanent residential addresses.

\section{Conclusion:}

One of the limitation of the study was the time-lag between treatment completion and interview which was around one year and might have resulted in a recall bias. The reasons for default and other relevant information could not elicited from patients who had migrated. However in conclusion, RNTCP was effective as revealed by the one-year of follow-up results. Periodic re-orientation training of Medical Officers and DOTS providers, ensuring proper supervision from TU to district level, review of performance and timely feedback regarding performance of each health unit, can be undertaken at the present moment for improvement of performance. Further multi centric studies in larger samples are required for a national evaluation of the programme.

\section{References}

[1]. Tuberculosis: Burden of the disease in India. TB India 2005 RNTCP Status Report.

[2]. Khatri GR. The revised national tuberculosis control programme: a status report on the first 100,000 patients. Indian J Tub 1999; 46: $157-66$.

[3]. Chadha SL, Bhagi RP. Treatment outcome in tuberculosis patients placed under directly observed treatment short course (DOTS): a cohort study. Indian J Tub 2000; 47: 155-8.

[4]. Yatin D, Danani U, Desai C. Relapse following directly observed therapy short course (DOTS): a follow-up study. Indian J Tub 2000; 47: 233-6.

[5]. Prasad R, Srivastawa SK, Ratan RK, Srivastawa P. Report on Revised National Tuberculosis Control Programme Urban Project in Lucknow. Indian J Tub 2000; 47: 159.

[6]. Kumareson JA, Ahsan Ali AKM, Parkkali LM. Tuberculosis control in Bangladesh: success of DOTS strategy. Int J Tuberc Lung Dis 1998; 2: 992-8.

[7]. Gaur SN, Dhingra VK. Tuberculosis in the elderly and their outcome under DOTS. Indian J Tub 2004; $51: 83-7$.

[8]. Jagota P, Chandrasekaran S, Sumathi G. Follow-up of pulmonary tuberculosis patients treated with short course chemotherapy through traditional birth attendants. Indian J Tub 1998; 45: 89-93. 
[9]. Vijay S, Balasangameswara VH, Jagannatha PS, Saroja VN, Kumar P. Treatment outcome and two and half years follow- up status of new smear positive patients treated under RNTCP. Indian J Tub 2004; 51: 199-208.

[10]. Chan-Yeung M, Noertjojo K, Tan J, Chan AL. Tuberculosis in the elderly in Hong Kong. Int J Tuberc Lung Dis 2002; 6: 771 - 9.

[11]. Connoly C, Reid A, Davies G, Strum W, McAdam KP, Wilkinson D. Relapse and mortality among HIV infected and uninfected tuberculosis patients, successfully treated with twice weekly directly observed therapy in Rural South Africa. AIDS 1999; 13: 15437.

[12]. Dhingra VK, Rajpal S, Aggarwal N, Aggarwal JK. Treatment of tuberculous pleural effusion and their satisfaction with DOTS: a one and a half year follow-up. Indian J Tub 2004; 51: 209-12

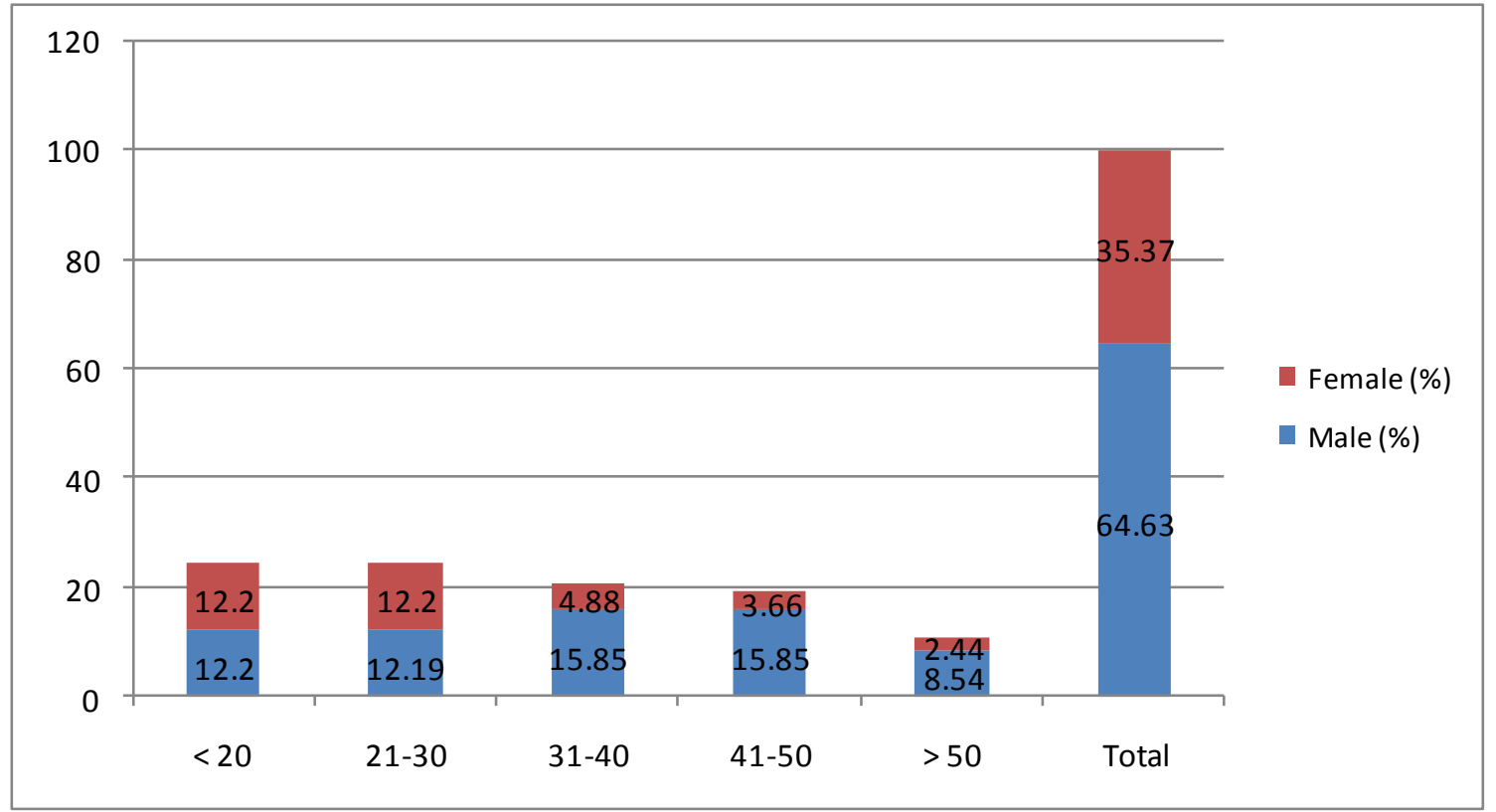

Fig 1: Age and sex distribution of tuberculosis patients registered for treatment in the period from January to December $2007(\mathrm{n}=82)$

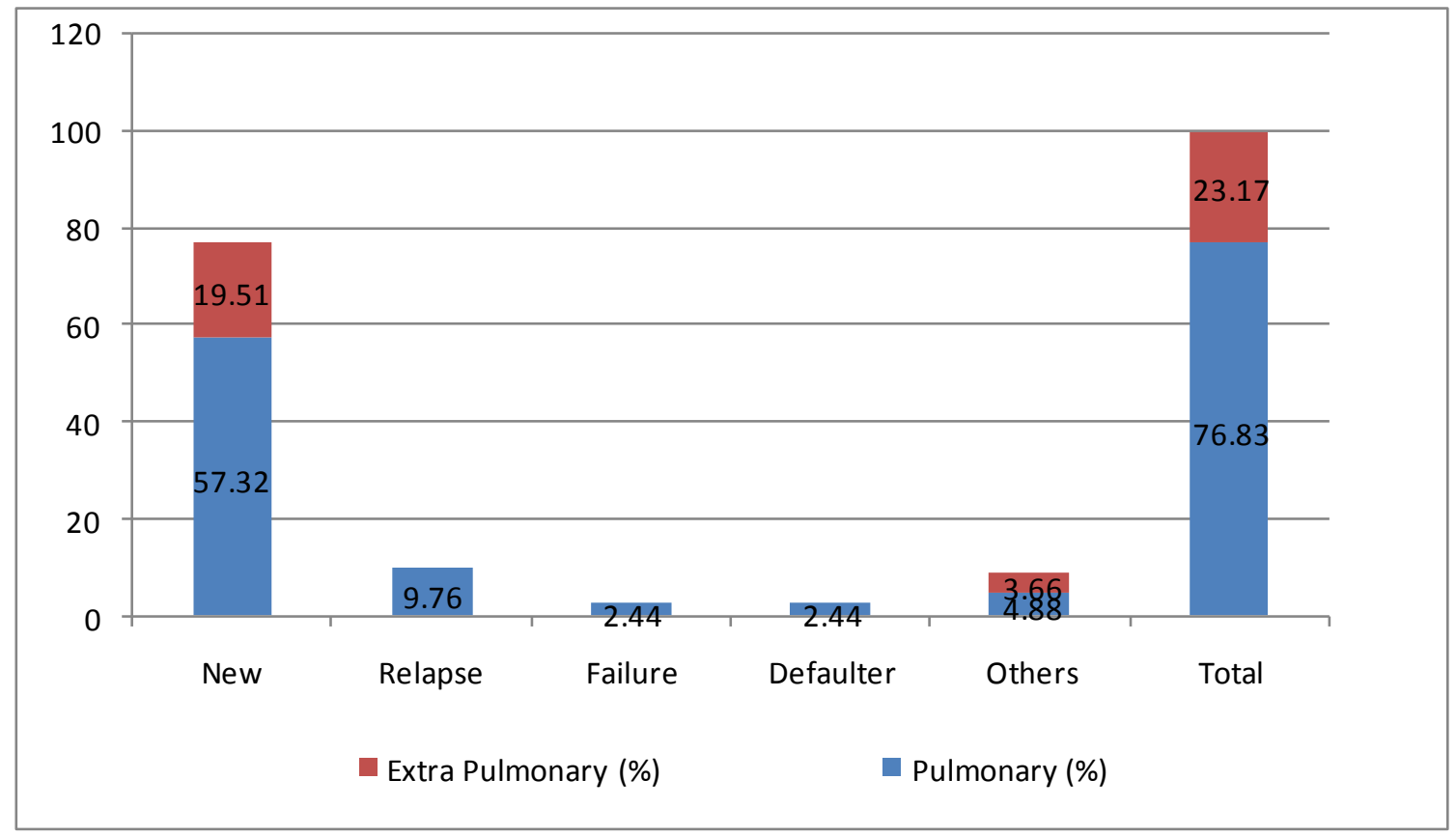

Fig. 2: Distribution of tuberculosis patients according to their type in DOTS $(\mathbf{n}=82)$

(* 'Others' include those patients who do not fit in any category according to the definition. Most of the patients among 'other' type were those who were previously on NTCP and after starting RNTCP M.O. decided to put under DOTS) 
Table 1: Distribution of sputum-positive tuberculosis cases according to their pre-treatment and follow up sputum examination result at 2 or 3 months $(n=49)$

\begin{tabular}{|lccccc|}
\hline Type of patient & $\begin{array}{c}\text { Pre-treatment } \\
\text { sputum positive } \\
\text { cases }\end{array}$ & $\begin{array}{c}\text { Sputum smear status at 2 or 3 months } \\
\text { Positive }\end{array}$ & Negative & Not available & $\begin{array}{c}\text { Sputum } \\
\text { conversion rate } \\
(\%)\end{array}$ \\
New & 37 & 3 & 27 & 7 & 72.97 \\
Relapse & 8 & 0 & 7 & 1 & 87.5 \\
Failure & 1 & 0 & 1 & 0 & 100 \\
Treatment after & 1 & 0 & 1 & 0 & 100 \\
default & 2 & 1 & 0 & 1 & 50.00 \\
Others $(*)$ & 49 & 4 & 36 & 0 & 73.47 \\
Total & & & & & \\
\hline
\end{tabular}

Table 2: Distribution of tuberculosis patients according to their treatment outcome $(n=82)$

\begin{tabular}{|c|c|c|c|c|c|c|c|c|}
\hline \multirow{2}{*}{$\begin{array}{c}\text { TB } \\
\text { classification }\end{array}$} & \multicolumn{8}{|c|}{ Number of patients } \\
\hline & Cat-I $\dagger$ & Cat-II $\dagger$ & Cat-III $\dagger$ & Failure & $\overline{\text { Defaulter }}$ & Died & Total & $\begin{array}{c}\text { Treatment } \\
\text { Success }(\%)\end{array}$ \\
\hline $\begin{array}{l}\text { Sm. Pos. } \\
\text { PTB }\end{array}$ & $37(36)$ & 11(9) & N.A. & 1 & 2 & 0 & 48 & $45(93.75)$ \\
\hline $\begin{array}{l}\text { Sm. Neg. } \\
\text { PTB }\end{array}$ & $7(6)$ & $5(4)$ & $3(3)$ & 0 & 1 & 1 & 15 & 13(86.67) \\
\hline $\begin{array}{c}\text { Extra } \\
\text { pulm. TB }\end{array}$ & $7(6)$ & $2(2)$ & $10(8)$ & 0 & 2 & 1 & 19 & $16(84.21)$ \\
\hline Total & $51(48)$ & $18(15)$ & $13(11)$ & $1(1.22 \%)$ & $5(6.1 \%)$ & $\begin{array}{l}2(2.4 \\
\%)\end{array}$ & 82 & $74(90.24)$ \\
\hline
\end{tabular}

$\uparrow$ Category and figures in parentheses denote no. of patients who achieved treatment success for each group.

Treatment success $=$ Cured + Treatment Completed

Table - 3: Socio-demographic information of Follow-up patients $(\mathbf{n}=60)$

\begin{tabular}{|c|c|c|c|c|}
\hline \multicolumn{2}{|c|}{ Socio demographic character } & Male $(\%)$ & Female $(\%)$ & Total $(\%)$ \\
\hline \multirow[t]{4}{*}{ Education } & Illiterate & $11(18.33)$ & $6(10.00)$ & $17(28.33)$ \\
\hline & Primary & $17(28.33)$ & $9(15.00)$ & $26(43.33)$ \\
\hline & Secondary & $8(13.33)$ & $3(5.00)$ & 11(18.33) \\
\hline & $>$ Secondary & $5(8.33)$ & $1(1.67)$ & $6(10.00)$ \\
\hline \multirow[t]{5}{*}{ Occupation } & Labour & $24(40.00)$ & $7(11.67)$ & $31(51.67)$ \\
\hline & Govt. Servant/Business & $5(8.33)$ & 0 & $5(8.33)$ \\
\hline & House wife & 0 & $8(13.33)$ & $8(13.33)$ \\
\hline & Others(student/retired) & $7(11.67)$ & $4(6.67)$ & 11(18.33) \\
\hline & Unemployed & $5(8.33)$ & 0 & $5(8.33)$ \\
\hline \multirow{3}{*}{$\begin{array}{l}\text { Percapita } \\
\text { income/month(Rs.) }\end{array}$} & $<500$ & $23(38.33)$ & 11(18.33) & $34(56.67)$ \\
\hline & $500-1000$ & $13(21.67)$ & $8(13.33)$ & $21(35.00)$ \\
\hline & $>1000$ & $5(8.33)$ & 0 & $5(8.33)$ \\
\hline \multirow[t]{2}{*}{ Type of family } & Nuclear & $30(50.00)$ & $12(20.00)$ & $42(70.00)$ \\
\hline & Joint & $11(18.33)$ & $7(11.67)$ & $18(30.00)$ \\
\hline
\end{tabular}

